\title{
Digital Phenotyping - A Case for Cognitive Functions and Dementia?
}

\author{
Christian Montag $^{1 *} \&$ Jon D. Elhai ${ }^{2}$ \\ 1 Department of Molecular Psychology, Institute of Psychology and Education, Ulm University, Germany \\ 2 Department of Psychology, and Department of Psychiatry, University of Toledo, Toledo, OH, USA
}

\begin{abstract}
Background: This article provides the reader with a brief background on recent advances in the field of Psychoinformatics. Psychoinformatics represents a merger between the disciplines of computer science and psychology, thus enabling researchers to, among other activities, conduct digital phenotyping while exploiting the ubiquitously available digital traces resulting from interaction with the Internet of Things (IoT). IoT describes a totally interconnected world, where everything from household appliances to smartphones are linked to each other via the Internet.

Objectives: In recent years, much work has been dedicated to the question of which psychological variables, in the realm of socio-demographics and personality, can be predicted from social media platform data and/or smartphones in general. These variables are of interest to researchers, because they have been associated with many important life variables such as longevity, health behaviour and job performance.

Methods: As research concerning cognition is an area of Psychoinformatics which has received comparatively less attention, the focus of the present article is on ideas regarding how cognitive functions, and more specifically dementia such as Alzheimer's Disease (AD), might co-vary with data from the IoT.

Results: It is demonstrated that different socio-demographic and psychological variables, including cognitive variables, can be predicted from digital footprints.

Conclusions: The application of methods from Psychoinformatics provides opportunities to improve diagnostics and monitoring of $\mathrm{AD}$ and other causes for dementia. The limitations of such approaches are also addressed in this article alongside relevant thoughts on ethical considerations.
\end{abstract}

Keywords: digital phenotyping, dementia, Alzheimer, Psychoinformatics, personality, mobile sensing, emotion

\section{Background}

According to recent data from the Alzheimer's Association (AA), (late onset) Alzheimer's disease $(\mathrm{AD})$ represented the $6^{\text {th }}$ leading cause of death in the USA in 2018. Moreover, it has been estimated by the AA that national cost of Alzheimer's and other dementias will probably rise from 305 billion US dollars in 2020 to a staggering 1.1 trillion dollars in 2050 (Alzheimer's Association, 2020). Such numbers can be supplemented by highly alarming $\mathrm{AD}$ rates in countries such as Germany, where costs are also likely to rise dramatically (e.g., Deutsche Alzheimer Gesellschaft, 2018).

$\mathrm{AD}$, which was first diagnosed in 1906 by German psychiatrist Alois Alzheimer, represents the most common cause of dementia resulting in memory loss (Goedert \& Spillantini, 2006). Beyond memory loss, several neuropsychiatric symptoms and behavioural impairments accompany dementia (Ismail et al., 2016). In the late stages of $\mathrm{AD}$, patients are not able to perform their everyday life activities alone and are dependent on 24 hour care. This incurs a high financial burden for society and great physical and emotional distress among afflicted patients and their relatives. Significantly, effective treatments for this devastating disorder remain elusive.

The biological mechanisms underlying this neurodegenerative disorder are still poorly understood, perhaps with the amyloid-beta hypothesis being the most prominent approach to understanding AD (Wang et al., 2017). Here, it has been proposed that an imbalanced metabolism of amyloid-beta might be at the heart of $\mathrm{AD}$, although this view has been challenged (Kepp, 2017). There is consensus among scientists that AD is multicausally influenced with both genetic and environmental factors playing a relevant role in the etiogenesis of $\mathrm{AD}^{1}$ (Huang \& Mucke, 2012; see also heritability estimates in Gatz et al., 1997). On the molecular genetic side in particular, genetic variations

Please note that we mainly speak of late onset AD in this article. For instance, we are aware that other genetic markers, as presented in the following, are of relevance to understand some cases of early onset $\mathrm{AD}$ and so forth. 
of the APOE gene resulting in the so called epsilon (e) e2, e3 and e4 alleles have been associated with AD (Corder et al., 1993; Montag et al., 2014). In detail, carrying one e4 allele results in a threefold risk of developing $\mathrm{AD}$, whereas carrying two copies of e4 results in a tenfold risk. Work by Kunz et al. (2015) demonstrated that young e4 allele carriers are more likely to have altered grid cell activity in the entorhinal cortex while performing a navigational memory task, hinting towards an early biomarker in predicting AD. Therefore, in the near future early Alzheimer diagnostics might begin in early adulthood giving persons at genetic risk of developing the condition the opportunity to adopt health behaviours including dietary practices and physical activity. Such interventions might counteract the genetic risk for AD (e.g. Reiner et al., 2013; Müller, 2015; Scarmeas et al., 2009).

As young adults strongly engage in smartphone use in their everyday lives (about 2.5 hours each day, see Montag et al., 2015), we believe that it is necessary and important to study human-smartphone-interaction patterns to provide insights into the development of dementia including AD starting early in life. This idea will be outlined in detail following a brief description of Psychoinformatics.

\section{A new discipline called Psycho- informatics}

Recent years have seen a rise in studies in the field of Psychoinformatics (Yarkoni, 2012; Markowetz et al., 2014). This new interdisciplinary research area applies methods from computer science in psychology and psychiatry to obtain insights into complex human behaviour. In the realm of Psychoinformatics, among other methods, app-based technologies are used to study human behaviour via digital traces left from human-smartphone-interaction (Miller, 2012). Here, studies have established links between phone use behaviour and personality (Chittaranjan et al., 2013; Montag et al., 2014; Stachl et al., 2018; Montag et al., 2019a), but also between length of daily WhatsApp usage and personality/ age/gender (Montag et al., 2015). Personality describes stable motivational, emotional and cognitive characteristics of a person across time and - to a lesser degree - different situations (for more on the complexities and challenges in relation to this concept see works by Bleidorn et al., 2018; Edmonds et al., 2008; Mischel \& Shoda, 1995; and Montag \& Panksepp, 2017. For the relevance of situation characteristics in personality science see Rauthmann et al., 2014). Beyond this work on smartphone-personality-links, social media platforms have been abundantly studied to predict person variables from digital traces such as Facebook "Likes" (Kosinski et al., 2013). In addition to the prediction of person characteristics from such "Likes", textmining has been applied to reveal insights into trait emotionality of a person (Schwartz et al., 2013; Settani \& Marengo, 2015). Use of specific words in posts on social media platforms provides insights into whether a person, e.g., is neurotic ${ }^{2}$ (manifested by often using words such as being depressed or anxious). Beyond Facebook other platforms are also noteworthy. A prominent example is Twitter, which also has been analyzed to reveal insights into personality (Ahmad \& Siddique, 2017; Quercia et al., 2011). For a recent overview on the use of data harvested from social media platforms to predict psychological variables, please see the work of Azucar et al. (2018), but also the new work by Marengo \& Montag (2020) in the present issue.

Clearly, these examples represent just the tip of the iceberg of what will come in the near future in the expanding new field of Psychoinformatics (Montag \& Elhai, 2019). Effectively, all data derived from the interaction with a completely connected world - the Internet of Things (IoT) - can be used to conduct digital phenotyping, hence enabling researchers to obtain insights into a person's trait or state variables. Notably, many researchers refer to digital phenotyping (Insel, 2018; Onnela \& Rauch, 2016; Torous et al., 2017) rather than Psychoinformatics (see also Montag et al., 2016), although both terms can be brought together. Whereas Psychoinformatics might describe a new research discipline, digital phenotyping currently represents one of the most often used applications in this interdisciplinary research field. One could say that a researcher aims to conduct digital phenotyping applying methods from Psychoinformatics.

Beyond the prominent examples from social media studies, researchers are also already including data from other activities of everyday life in their models to reveal insights into psychological phenomena. To name a small number of recent examples, one study predicted the gender of a driver from motor vehicle driving behaviour including velocity, gas pedal actuation, and steering wheel angle (Stachl \& Bühner, 2015). A noteworthy new work by Cao et al. (2018) even predicted orderliness from the campus behaviour of students in China. Here, temporal records of showering and meal intake (recorded via a smartcard at the University of Electronic Science and Technology of China in Chengdu in $n$ $=18,960$ students) gave insights into orderliness. Higher orderliness (regular showering and meal intake) itself was a good predictor of better academic performance in this work. In our opinion, this example from China illustrates nicely the potential of data mining from ubiquitously available data stemming from the IoT.

\section{How digital phenotyping might help in the early diagnosis of Alzheimer's Disease (AD) and other causes of dementia, as well as monitoring its progression.}

In principle, it will also be possible to use data from the IoT in the realm of $\mathrm{AD}$ or general dementia diagnostics. This endeavor could be undertaken not only to uncover early markers for AD in the current smartphone-using generation, but also to monitor

\footnotetext{
Neuroticism represents one of the Big Five dimensions carved out in personality psychology against the background of a lexical approach.
} 
cognitive functions over a longer time period in elderly patients in the transit zone from mild cognitive impairment (MCI) to $\mathrm{AD}$. As a consequence, the latter approach will also enable both scientists and practitioners to obtain insights into the course of $\mathrm{AD}$ when it has been diagnosed. Any such research endeavor will without doubt be very complex, because different causes of dementia exist, with (late onset) Alzheimer's being perhaps the most prevalent. This raises the question of whether digital footprints left on the smartphone can provide insights into the different causes of dementia of relevance in the aforementioned transit zone from MCI to a demented state of mind. MCI is characterized by both subjective and objective cognitive impairment (but not dementia) and frequently is accompanied by neuropsychiatric symptoms such as negative mood, lack of motivation and anxiety. Interestingly, those patients which display both MCI and anxiety symptoms are much more likely to develop Alzheimer's disease than those that possess MCI but lack anxiety symptoms ( $83.3 \%$ vs. $40.9 \%$; Palmer et al., 2007). Hence, it will be of utmost importance to not only obtain insights into the cognitive state of a person when mining smartphone or IoT data, but also into the affective state, because both variable sets are of high interest in efforts to predict the probability of transiting from MCI to dementia. In this context, another work by Ismael et al. (2016) is noteworthy, because it not only proposes the relevance of understanding the neuropsychiatric symptoms visible in MCI, but also stresses the importance of mild behavioural impairment (MBI) criteria such as changes in social behaviour and speech, likely to leave their trace in smartphone variables (e.g. changes in contacting persons via the smartphone or use of more stereotyped speech in smartphone messages). Stereotyped language might also be directly investigated, when a patient is speaking to IoT devices such as Amazon's Alexa or Apple's Siri. In this context, we believe it is also of interest to infer personality from the smartphone data, because high neuroticism (via its link to higher risk for depression) and low conscientiousness are well-known risk factors in developing dementia (Low et al., 2013). Therefore, the aforementioned studies showing links between personality and digital footprints are of high relevance for dementia research. In addition to these works, the "Lancet Commission on Dementia Call for Action", which outlines modifiable risk factors for dementia over the life span, is of significant relevance. While in early life the variable of (less) education is mentioned, in midlife hearing loss, hypertension and obesity are advanced as important risk factors. In late life factors such as smoking, depression, physical inactivity, social isolation and diabetes are particularly noteworthy (Orgeta et al., 2019). Beyond this, as motoric and visual dysfunctions might leave their traces in the human-smartphone-interaction, this also represents a relevant research area. Therefore, establishing links between these variables and digital footprints at different life stages might also indirectly produce insights on risks for dementia.

From a neuroscientist's perspective, and in line with work by Kunz et al. (2015), it would be interesting to know if young persons at genetic risk for $\mathrm{AD}$ behave differently in everyday life.
Such a research design would lead to a fusion of bio-psychological and information technology data, perhaps one of the most promising and exciting new areas in the health sciences (see Figure 1). Building on the study conducted by Kunz et al. (2015) which investigated navigational-memory abilities, an interesting idea would be to test for differences in global positioning system (GPS) related variables tracked via smartphone depending on the aforementioned APOE genotype. Such GPS variables would also provide insights into an active lifestyle, providing information on the extent to which an individual is travelling (in terms of traveled miles/km each day). Operation systems of modern smartphones also include health data functions such as calories burned per day or number of footsteps detected via the smartphone's sensors; such variables might supplement these GPS data sets. It should be noted, however, that interpreting such data will not be easy, as a (highly) active lifestyle might also be an indicator of a stressful episode in a person's life. This also demonstrates that, beyond the data that can be derived from Psychoinformatics, a myriad of other (classic) variables, including self-report/ neuropsychological test measures, still need to be considered to gain an accurate picture of a person's health condition. Without doubt only patterns of variables will be able to give valid and reliable insights into psychological/psychiatric variables. In contrast a single variable alone will not be able to explain more than a few percent of the variance in complex psychological/psychiatric phenotypes. For example, the shared variance between a call variable from the smartphone and the personality trait of extraversion is approximately $10 \%$ (Montag et al., 2014; Montag et al., 2019a). To illustrate this further, Markowetz et al. (2014) hypothesized that smartphone use variables might provide insights into the depressed state of a person (probably also of an $\mathrm{AD}$ patient). In the context of $\mathrm{AD}$, dementia patients often show signs of depression when being in the transit zone from MCI to full blown $\mathrm{AD}$ because they are consciously experiencing their own cognitive decline (for links between $\mathrm{AD}$ and depression see the studies by Modrego \& Ferrández (2004) and Ownby et al. (2006)). What kind of pattern of smartphone variables could reflect a depressed state? For example, a person's lack of motivation to engage in everyday life activities could result in lower GPS activity. His/ her high sadness could manifest in higher usage of negative text content in social media channels, and a lack of energy for social communication/social withdrawal could be reflected by the individual contacting their social network via their phone to a lesser degree compared to the pre-depressed state (see also Elhai et al., 2018; Saeb et al., 2015). Again, a single variable taken alone will not help to establish predictions with a high degree of accuracy.

As with $\mathrm{AD}$ diagnostics, the focus lies in particular on monitoring the cognitive functions of a person (but also taking into account the importance of examining affect as mentioned above). We believe that the smartphone might provide an interesting source of research for understanding individual differences in cognitive variables (for feasibility see new work by Dagum (2017) and another opinion piece by Kourtis et al. (2018)). Firstly, textmining of a person's diverse text messages might re- 
sult in a valid estimate of how many words a person uses in everyday life. By monitoring a person's word usage longitudinally, the treating physician or neurologist can investigate how many words were used before AD was diagnosed, and how their usage of different words in everyday life shrinks with the progression of $\mathrm{AD}$. Second, a source less considered to date in monitoring the cognitive functions of a person is his/her smartphone interaction (Montag, Reuter \& Markowetz, 2017). In our own work it has been demonstrated in a sample of approximately one hundred students that the smartphone-screen is unlocked an average of about 50 times a day (Montag et al., 2019b). In a year this would result in 18,250 unlocks (50 unlocks x 365 days). Imagine now that instead of using a single simple swipe to unlock the phone, a user is required to complete a neuropsychological test. Implementing such a task would result in an impressive amount of longitudinal data providing insights into changes and/or stability of a person's cognitive functions (see also Montag, Reuter \& Markowetz, 2017). Again, these types of activities will need to be treated very cautiously in the near future, because research has yet to develop answers to the question: which neuropsychological tasks should be implemented in such a scenario? Which tasks will be most sensitive in terms of properly diagnosing cognitive decline and indicating progress of $\mathrm{AD}$ ?

Aside from this, psychometric quality in terms of validity and reliability needs to be ensured for such cognitive unlock-screenmeasures. In short, will data derived from the smartphone be as valid and reliable as that derived from a carefully implemented neuropsychological measure in a strict lab setting? Obviously, much work needs to be conducted to establish such sound (mobile) cognitive measures. Nevertheless, we are convinced that even when persons play through these one-trial-unlock-tasks in the manifold different situations of everyday life (such as being on a crowded bus or distracted by factors in the environment), the sheer size of available data should reduce the errors in measurement and result in generally good insights into the cognitive ability of a person over the course of time.

As cognitive ability ${ }^{3}$ arises from the brain, human-smartphone-interaction data might not only provide insights into underlying psychological states, but indirectly also into (dys-) functional brain mechanisms. Early work demonstrated the feasibility of linking both molecular genetic and MRI data to smartphone use variables. Work by Sariyska et al. (2018) demonstrated that a genetic variant of the oxytocin receptor (OXTR) gene might be linked to the size of a person's (active) social network. Note that the sample size of this study was rather small and these findings thus need to be replicated by independent work groups. For some readers it might sound like a futuristic vision to infer the molecular genetic make-up of a person from

\footnotetext{
Here we use cognitive ability as a broad term. In psychology many different cognitive functions are investigated, perhaps most prominently executive functions comprising working memory, task switching and behavioural inhibition (Hofmann et al., 2012). But see also some relationships between executive functions and intelligence (Friedman et al., 2006).
}

the study of digital footprints. We partially share this opinion in relation to polygenetically influenced phenotypes in psychology also shaped by the environment (Montag \& Reuter, 2014), but again see the feasibility study by Sariyska et al. (2018). For neurodegenerative disorders, however, the situation may be somewhat different, because here genetic variants exert higher influence compared to the effects of a single genetic variant on a trait such as personality (again being influenced by hundred of genetic variants shaped by the environment). In particular, this should be true for monogenetically inherited disorders such as Chorea Huntington (e.g. Andrew et al., 1993). Beyond the OXTR gene smartphone paper, a study by Montag et al. (2017) observed a robust link between lower gray matter volume of the nucleus accumbens and longer/higher frequent use of the Facebook app installed on the smartphones of study participants. Although these statistically significant associations could "only" be established at the group level (and causality has not been established), in the future accuracy rates might increase with respect to individual diagnostics. Again, this will only happen when patterns of variables are be taken into account (see argumentation above). In sum, we believe that the time is ripe to investigate both psychological and biological variables in the context of digital phenotyping. Hence, bio/neuro-psycho-tech and info-tech are merging into the area of Psycho(neuro)informatics (Montag et al, 2016). Please see also Figure 1.

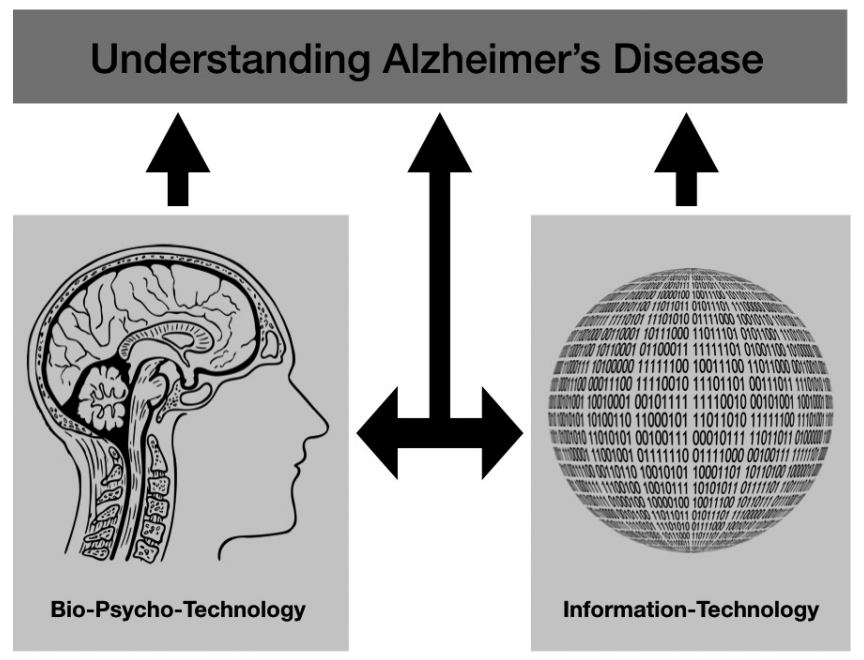

Figure 1: Whereas in the past Bio-Psycho-Technology data were investigated individually from psychologists, psychiatrists, neurologists or computer scientists in the context of Alzheimer's Disease (AD), new research approaches are applied to derive - by means of a combination of Bio-Psycho- and Information Technology data - insights into AD (images courtesy of licence free picture platform pixelbay.com).

\section{Limitations}

Although the future of Psycho(neuro)informatics seems to be bright, many challenges must be overcome before this new interdisciplinary research area can blossom. Psychologists/psy- 
chiatrists/neurologists and computer scientists have different publication cultures (e.g. conference proceeding publications in computer science) and not all scientists from each distinct research area are necessarily aware of what is published in the other discipline. Beyond this, prediction accuracy varies strongly depending both on the specific digital trace investigated and the to-be predicted psychological/psychiatric/neurological variable. The work by Azucar et al. (2018) concluded that "the predictive power of digital footprints over personality traits is in line with the standard "correlational upper-limit" for behaviour to predict personality, with correlations ranging from 0.29 (Agreeableness) to 0.40 (Extraversion)" (p. 150). Other variables such as gender can be much more accurately predicted from Facebook "Likes" or the aforementioned motor vehicle data. In the work by Kosinksi et al. (2013) accuracy rates for gender predicted from Facebook "Likes" were .93. Although this estimate is much better than the figures presented in the summary by Azucar et al. (2018), this approach still does not result in perfectly accurate predictions. Fittingly, Stachl \& Bühner's (2015) work on motor vehicle behaviour and gender yielded the insight that their "model is more successful in classification of males (positive class) in comparison with females." (p. 5590).

A further issue concerns the statistical approaches used to analyse data derived from the IoT. Many researchers in the life sciences have primarily applied classic inferential statistics to obtain insights from their collected data. But classic inferential statistics are only partly useful in terms of achieving higher accuracy rates from the statistical models. Therefore, other approaches such as machine learning need also to be applied to more effectively analyse the data. This will require the acquisition of new statistical skills for those working in Psychoinformatics.

Montag \& Elhai (2019) note the importance of keeping expectations in check about this new digital data layer. While both authors are convinced that digital phenotyping via Psychoinformatics represents a powerful layer, it is "only" a further data layer to be collected and applied by scientists to understand complex human behaviour. Taking information from a digital layer derived via methods from Psychoinformatics alone to predict human behaviour might result in an overly narrow view of human nature, and ultimately risks generating incorrect predictions.

A further problem of applying digital phenotyping in health care and other relevant areas relates to questions concerning the generalisability of observed associations between digital traces and a psychic variable. Even if a researcher reveals a robust set of variables linked to a psychological or psychiatry trait/state, it is not clear if this translates easily to other populations. Scientists always need to gather new data to infer psychological variables from digital traces to ascertain if a certain association remains valid. This is very relevant, because in the contemporary fastmoving world the topics people discuss on social media change on a very regular basis - the topics discussed a year ago are unlikely to be the same as those being discussed today. Hence, some facets of digital phenotyping (e.g. relying on textmining of social media messages) might underlie more rapid changes over time concerning the validity and reliability of established associations, because of advances in technology. In this limitation section we also wish to explicitly mention problems in the study of Alzheimer's Disease and other dementias. First and foremost, the current generation of patients suffering from dementia are not "digital natives", and hence many of them do not own a smartphone - or if they do, they did not learn to use it "naturally". Hence, much of the relevant research on dementia can only be conducted when the generation of digital natives and the somewhat older digital immigrants reach the age at which dementia becomes a critical topic. Another important aspect of this research will be to fully grasp the different stages of dementia, from preclinical to late stages (Förstl \& Kurz, 1999), from the study of digital footprints. Beyond this, it is relevant that there are different causes of dementia. This opinion piece has strongly focused on (late onset) Alzheimer's Disease as the most common cause for dementia. Nevertheless, Psychoinformatics might be particularly successful in carving out co-varying patterns with frontotemporal dementia in the near future (Ratnavalli et al., 2002), because its onset is earlier compared to (late onset) Alzheimer's, and the current generation of smartphone users may soon be facing neurodegenerative disorders with earlier onset (Neary et al., 2005; but note that an early form of Alzheimer's Disease also exists, which has not been discussed in this article).

\section{Ethical considerations}

Given the power that Psychoinformatics can have on psychodiagnostics, misuse of digital phenotyping has the potential to facilitate unethical practices (Montag, Sindermann \& Baumeister, 2020). Among these are influencing political or marketing campaigns via microtargeting. Insurance issues are also significant in this regard (e.g. Kosinski et al., 2015; Matz \& Netzer, 2017; Matz et al., 2017). As this article focuses on $\mathrm{AD}$ and other causes of dementia, we stress in particular the latter point. Without doubt the inclusion of Psychoinformatics in the psychodiagnostic process of dementia brings advantages in terms of better and more costeffective monitoring of cognitive decline on a longitudinal basis. However, a framework underpinned by governmental regulation is needed to secure data relating to individual cognitive decline. Insurance companies should not be allowed to utilize these data in decisions regarding whether a person will obtain health insurance. The same should be true for the costs of such insurance. Beyond regulation of the application of digital phenotyping in the context of insurance, human resources departments should not be permitted to administer such digital variables in hiring decisions (or at least the tracking level needs to be made very transparent to the persons undertaking the application process). In one prominent case from the United States, the retailer Target determined via digital phenotyping that a young woman was pregnant before her father (Forbes, 2012). These examples illustrate that the area of digital phenotyping is accompanied by complex ethical problems, which cannot be tackled in a short opin- 
ion piece such as this. What is presented on the ethical issues in digital phenotyping in this article is limited and provides only a brief overview of this highly relevant and critical area. For further reading we point to recent published works dealing with privacy issues (Kargl et al., 2019) and ethical views from a practitioner's perspective (Dagum \& Montag, 2019) in the age of digital phenotyping (by others critically referred to as surveillance capitalism; Foster \& McChesney, 2014; Zuboff, 2015, 2019). Inferring (genetic) risk for developing dementia from digital footprints also raises problems with respect to genetic counseling: e.g., carrying the e4 risk allele on the APOE gene goes along with heightened risk for developing Alzheimer's, but we speak of risk, not a certainty. Therefore: do people want to know about their genetic risk of developing the condition? If they are unaware of their risk, will they act to reduce risk factors across the life span as is noted in the work of Orgeta et al. (2019)?

Although misuse of digital data represents a problem, the ethical use of techniques from Psychoinformatics may also be valid in some of the above discussed areas, as long as the inclusion of health and related data was banned. For example, in a hiring process a company may want to assess intelligence from data derived from the IoT. This procedure could be permitted, as it is common practice in many companies for applicants to undergo intelligence testing, as intelligence is a good predictor of job performance (e.g. Ree \& Earles, 1992). After a few years of analyzing data from the IoT, this method may even come to represent a more effective intelligence test, as a one-time assessment of intelligence which takes place in a company environment might be biased by the individual's test anxiety. It is clear that there is a thin line between use and misuse of digital phenotyping. Establishing trust through absolute transparency will be key to usage of digital phenotyping in a given business and research area. There is no other way than to make sure that a person understands exactly what is tracked and for what period of time. Moreover, a person must always have the option to not give consent to such a procedure (without fear of negative consequences). Furthermore, the depth of tracking should also be regulated. From a privacy aspect it makes a difference if the content of a message is read in full, or if on a meta-level the variable "number of positive/negative words" is counted. These few examples demonstrate how difficult it will be to answer many of the pressing questions in the field of Psychoinformatics, in particular with respect to the treatment of brain disorders. Without a visible public and political debate on how such data should be implemented in diagnostic processes in the near future, new data and privacy scandals such as the recent incidents around the Facebook-Cambridge Analytica scandal are very likely to occur (Wikipedia.org, 2019).

\section{References}

Alzheimer's Association (2020). https://www.alz.org/alzheimers-dementia/facts-figures (accessed on 1st May 2020)

Ahmad, N., \& Siddique, J. (2017). Personality Assessment using Twitter Tweets. Procedia Computer Science, 112, 1964-1973. https://doi. org/10.1016/j.procs.2017.08.067
Andrew, S. E., Goldberg, Y. P., Kremer, B., Telenius, H., Theilmann, J., Adam, S., Starr, E., Squitieri, F., Lin, B., Kalchman, M. A., Graham, R. K., \& Hayden, M. R. (1993). The relationship between trinucleotide (CAG) repeat length and clinical features of Huntington's disease. Nature Genetics, 4(4), 398-403. https://doi.org/10.1038/ng0893-398

Azucar, D., Marengo, D., \& Settanni, M. (2018). Predicting the Big 5 personality traits from digital footprints on social media: A metaanalysis. Personality and Individual Differences, 124, 150-159. https://doi.org/10.1016/j.paid.2017.12.018

Bleidorn, W., Hopwood, C. J., \& Lucas, R. E. (2018). Life Events and Personality Trait Change. Journal of Personality, 86(1), 83-96. https:// doi.org/10.1111/jopy.12286

Cao, Y., Gao, J., Lian, D., Rong, Z., Shi, J., Wang, Q., Wu, Y., Yao, H., \& Zhou, T. (2018). Orderliness predicts academic performance: Behavioural analysis on campus lifestyle. Journal of The Royal Society Interface, 15(146), 20180210. https://doi.org/10.1098/rsif.2018.0210

Chittaranjan, G., Blom, J., \& Gatica-Perez, D. (2013). Mining large-scale smartphone data for personality studies. Personal and Ubiquitous Computing, 17(3), 433-450. https://doi.org/10.1007/s00779-0110490-1

Corder, E. H., Saunders, A. M., Strittmatter, W. J., Schmechel, D. E., Gaskell, P. C., Small, G. W., Roses, A. D., Haines, J. L., \& Pericak-Vance, M. A. (1993). Gene dose of apolipoprotein E type 4 allele and the risk of Alzheimer's disease in late onset families. Science (New York, N.Y.), 261(5123), 921-923. https://doi.org/10.1126/science.8346443

Dagum, P. (2018). Digital biomarkers of cognitive function. Npj Digital Medicine, 1(1), 1-3. https://doi.org/10.1038/s41746-018-0018-4

Dagum, P., \& Montag, C. (2019). Ethical Considerations of Digital Phenotyping from the Perspective of a Healthcare Practitioner. In H. Baumeister \& C. Montag (Eds.), Digital Phenotyping and Mobile Sensing: New Developments in Psychoinformatics (pp. 13-28). Springer International Publishing. https://doi.org/10.1007/978-3030-31620-4_2

Deutsche Alzheimer Gesellschaft (2018). https://www.deutsche-alzheimer.de/fileadmin/alz/pdf/factsheets/infoblatt1_haeufigkeit_demenzerkrankungen_dalzg.pdf (accessed on 1st May 2020)

Edmonds, G. W., Jackson, J. J., Fayard, J. V., \& Roberts, B. W. (2008). Is character fate, or is there hope to change my personality yet? Social and Personality Psychology Compass, 2(1), 399-413. https://doi. org/10.1111/j.1751-9004.2007.00037.x

Elhai, J. D., Tiamiyu, M., Weeks, J., Levine, J., Picard, K., \& Hall, B. J. (2018). Depression and emotion regulation predict objective smartphone use measured over one week. Personality and Individual Differences, 133, 21-28. https://doi.org/10.1016/j.paid.2017.04.051

Forbes (2012). https://www.forbes.com/sites/kashmirhill/2012/02/16/ how-target-figured-out-a-teen-girl-was-pregnant-before-her-father-did/\#5f43f0896668 (accessed on 1st May 2020).

Förstl, H., \& Kurz, A. (1999). Clinical features of Alzheimer's disease. European Archives of Psychiatry and Clinical Neuroscience, 249(6), 288-290. https://doi.org/10.1007/s004060050101

Foster, J. B., \& McChesney, R. W. (2014). Surveillance capitalism: Monopoly-finance capital, the military-industrial complex, and the digital age. Monthly Review, 66(3), 1-31. https://monthlyreview. org/2014/07/01/surveillance-capitalism/

Friedman, N. P., Miyake, A., Corley, R. P., Young, S. E., Defries, J. C., \& Hewitt, J. K. (2006). Not all executive functions are related to intelligence. Psychological Science, 17(2), 172-179. https://doi. org/10.1111/j.1467-9280.2006.01681.x

Gatz, M., Pedersen, N. L., Berg, S., Johansson, B., Johansson, K., Mortimer, J. A., Posner, S. F., Viitanen, M., Winblad, B., \& Ahlbom, A. (1997). Heritability for Alzheimer's disease: The study of dementia in Swedish twins. The Journals of Gerontology. Series A, Biological Sciences and Medical Sciences, 52(2), M117-125. https://doi. org/10.1093/gerona/52a.2.m117

Goedert, M., \& Spillantini, M. G. (2006). A century of Alzheimer's disease. Science (New York, N.Y.), 314(5800), 777-781. https://doi. org/10.1126/science.1132814

Hofmann, W., Schmeichel, B. J., \& Baddeley, A. D. (2012). Executive functions and self-regulation. Trends in Cognitive Sciences, 16(3), 174-180. https://doi.org/10.1016/j.tics.2012.01.006 
Huang, Y., \& Mucke, L. (2012). Alzheimer mechanisms and therapeutic strategies. Cell, 148(6), 1204-1222. https://doi.org/10.1016/j. cell.2012.02.040

Insel, T. R. (2017). Digital Phenotyping: Technology for a New Science of Behavior. JAMA, 318(13), 1215-1216. https://doi.org/10.1001/ jama.2017.11295

Ismail, Z., Smith, E. E., Geda, Y., Sultzer, D., Brodaty, H., Smith, G., Agüera-Ortiz, L., Sweet, R., Miller, D., Lyketsos, C. G., \& ISTAART Neuropsychiatric Symptoms Professional Interest Area. (2016). Neuropsychiatric symptoms as early manifestations of emergent dementia: Provisional diagnostic criteria for mild behavioral impairment. Alzheimer's \& Dementia: The Journal of the Alzheimer's Association, 12(2), 195-202. https://doi.org/10.1016/j.jalz.2015.05.017

Kargl, F., van der Heijden, R. W., Erb, B., \& Bösch, C. (2019). Privacy in Mobile Sensing. In H. Baumeister \& C. Montag (Eds.), Digital Phenotyping and Mobile Sensing: New Developments in Psychoinformatics (pp. 3-12). Springer International Publishing. https://doi. org/10.1007/978-3-030-31620-4_1

Kepp, K. P. (2017). Ten Challenges of the Amyloid Hypothesis of Alzheimer's Disease. Journal of Alzheimer's Disease: JAD, 55(2), 447457. https://doi.org/10.3233/JAD-160550

Kosinski, M., Matz, S. C., Gosling, S. D., Popov, V., \& Stillwell, D. (2015). Facebook as a research tool for the social sciences: Opportunities, challenges, ethical considerations, and practical guidelines. The American Psychologist, 70(6), 543-556. https://doi.org/10.1037/ a0039210

Kosinski, M., Stillwell, D., \& Graepel, T. (2013). Private traits and attributes are predictable from digital records of human behavior. Proceedings of the National Academy of Sciences of the United States of America, 110(15), 5802-5805. https://doi.org/10.1073/ pnas. 1218772110

Kourtis, L. C., Regele, O. B., Wright, J. M., \& Jones, G. B. (2019). Digital biomarkers for Alzheimer's disease: The mobile/ wearable devices opportunity. NPJ Digital Medicine, 2. https://doi.org/10.1038/ s41746-019-0084-2

Kunz, L., Schröder, T. N., Lee, H., Montag, C., Lachmann, B., Sariyska, R., Reuter, M., Stirnberg, R., Stöcker, T., Messing-Floeter, P. C., Fell, J., Doeller, C. F., \& Axmacher, N. (2015). Reduced grid-cell-like representations in adults at genetic risk for Alzheimer's disease. Science (New York, N.Y.), 350(6259), 430-433. https://doi.org/10.1126/ science.aac 8128

Low, L.-F., Harrison, F., \& Lackersteen, S. M. (2013). Does personality affect risk for dementia? A systematic review and meta-analysis. The American Journal of Geriatric Psychiatry: Official Journal of the American Association for Geriatric Psychiatry, 21(8), 713-728. https://doi.org/10.1016/j.jagp.2012.08.004

Marengo, D., \& Montag, C. (2020). Digital Phenotyping of Big Five Personality Traits via Facebook Data Mining: A Meta-Analysis. Digital Psychology, 1(1), 52-63.

Markowetz, A., Błaszkiewicz, K., Montag, C., Switala, C., \& Schlaepfer, T. E. (2014). Psycho-informatics: Big Data shaping modern psychometrics. Medical Hypotheses, 82(4), 405-411. https://doi. org/10.1016/j.mehy.2013.11.030

Matz, S. C., Kosinski, M., Nave, G., \& Stillwell, D. J. (2017). Psychological targeting as an effective approach to digital mass persuasion. Proceedings of the National Academy of Sciences of the United States of America, 114(48), 12714-12719. https://doi.org/10.1073/ pnas. 1710966114

Matz, S., \& Netzer, O. (2017). Using Big Data as a window into consumers' psychology. Current Opinion in Behavioral Sciences, 18, 7-12. https://doi.org/10.1016/j.cobeha.2017.05.009

Miller, G. (2012). The Smartphone Psychology Manifesto: Perspectives on Psychological Science. https://doi.org/10.1177/1745691612441215

Mischel, W., \& Shoda, Y. (1995). A cognitive-affective system theory of personality: Reconceptualizing situations, dispositions, dynamics, and invariance in personality structure. Psychological Review, 102(2), 246-268. https://doi.org/10.1037/0033-295X.102.2.246

Modrego, P. J., \& Ferrández, J. (2004). Depression in patients with mild cognitive impairment increases the risk of developing dementia of
Alzheimer type: A prospective cohort study. Archives of Neurology, 61(8), 1290-1293. https://doi.org/10.1001/archneur.61.8.1290

Montag, C., Baumeister, H., Kannen, C., Sariyska, R., Meßner, E.-M., \& Brand, M. (2019a). Concept, Possibilities and Pilot-Testing of a New Smartphone Application for the Social and Life Sciences to Study Human Behavior Including Validation Data from Personality Psychology. J - Multidisciplinary Scientific Journal, 2(2), 102-115. https://doi.org/10.3390/j2020008

Montag, C., Baumeister, H., Kannen, C., Sariyska, R., Rathner, E.-M., \& Brand, M. (2019b). Higher number of screen unlocks is positively linked to smartphone-use disorder: A real-world tracking approach. Journal of Behavioral Addictions, 8, 57-57.

Montag, C., Błaszkiewicz, K., Lachmann, B., Andone, I., Sariyska, R., Trendafilov, B., Reuter, M., \& Markowetz, A. (2014). Correlating Personality and Actual Phone Usage. Journal of Individual Differences, 35(3), 158-165. https://doi.org/10.1027/1614-0001/a000139

Montag, C., Błaszkiewicz, K., Sariyska, R., Lachmann, B., Andone, I., Trendafilov, B., Eibes, M., \& Markowetz, A. (2015). Smartphone usage in the 21st century: Who is active on WhatsApp? BMC Research Notes, 8(1), 331. https://doi.org/10.1186/s13104-015-1280-z

Montag, C., Duke, É., \& Markowetz, A. (2016). Toward Psychoinformatics: Computer Science Meets Psychology [Review Article]. Computational and Mathematical Methods in Medicine; Hindawi. https:// doi.org/10.1155/2016/2983685

Montag, C., \& Elhai, J. D. (2019). A new agenda for personality psychology in the digital age? Personality and Individual Differences, 147, 128-134. https://doi.org/10.1016/j.paid.2019.03.045

Montag, C., Markowetz, A., Blaszkiewicz, K., Andone, I., Lachmann, B. Sariyska, R., Trendafilov, B., Eibes, M., Kolb, J., Reuter, M., Weber, B., \& Markett, S. (2017). Facebook usage on smartphones and gray matter volume of the nucleus accumbens. Behavioural Brain Research, 329, 221-228. https://doi.org/10.1016/j.bbr.2017.04.035

Montag, C., Kunz, L., Axmacher, N., Sariyska, R., Lachmann, B., \& Reuter, M. (2014). Common genetic variation of the APOE gene and personality. BMC Neuroscience, 15(1), 64. https://doi.org/10.1186/14712202-15-64

Montag, C., \& Panksepp, J. (2017). Primary Emotional Systems and Personality: An Evolutionary Perspective. Frontiers in Psychology, 8. https://doi.org/10.3389/fpsyg.2017.00464

Montag, C., \& Reuter, M. (2014). Disentangling the molecular genetic basis of personality: From monoamines to neuropeptides. Neuroscience and Biobehavioral Reviews, 43, 228-239. https://doi org/10.1016/j.neubiorev.2014.04.006

Montag, C., Reuter, M., \& Markowetz, A. (2017). The Impact of Psychoinformatics on Internet Addiction Including New Evidence. In C. Montag \& M. Reuter (Eds.), Internet Addiction: Neuroscientific Approaches and Therapeutical Implications Including Smartphone Addiction (pp. 221-229). Springer International Publishing. https:// doi.org/10.1007/978-3-319-46276-9_13

Montag, C., Sindermann, C., \& Baumeister, H. (2020). Digital phenotyping in psychological and medical sciences: A reflection about necessary prerequisites to reduce harm and increase benefits. Current Opinion in Psychology, 36, 19-24. https://doi.org/10.1016/j.copsyc.2020.03.013

Müller, T. (2015). Drei Stunden Sport pro Woche stabilisieren Alzheimer-Kranke. DNP - Der Neurologe und Psychiater, 16(7), 12-12. https://doi.org/10.1007/s15202-015-0849-7

Neary, D., Snowden, J., \& Mann, D. (2005). Frontotemporal dementia. The Lancet Neurology, 4(11), 771-780. https://doi.org/10.1016/ S1474-4422(05)70223-4

Onnela, J.-P., \& Rauch, S. L. (2016). Harnessing Smartphone-Based Digital Phenotyping to Enhance Behavioral and Mental Health. Neuropsychopharmacology, 41(7), 1691-1696. https://doi.org/10.1038/ npp. 2016.7

Orgeta, V., Mukadam, N., Sommerlad, A., \& Livingston, G. (2019). The Lancet Commission on Dementia Prevention, Intervention, and Care: A call for action. Irish Journal of Psychological Medicine, 36(2), 85-88. https://doi.org/10.1017/ipm.2018.4

Ownby, R. L., Crocco, E., Acevedo, A., John, V., \& Loewenstein, D. 
(2006). Depression and risk for Alzheimer disease: Systematic review, meta-analysis, and metaregression analysis. Archives of General Psychiatry, 63(5), 530-538. https://doi.org/10.1001/archpsyc.63.5.530

Palmer, K., Berger, A. K., Monastero, R., Winblad, B., Bäckman, L., \& Fratiglioni, L. (2007). Predictors of progression from mild cognitive impairment to Alzheimer disease. Neurology, 68(19), 1596-1602. https://doi.org/10.1212/01.wnl.0000260968.92345.3f

Quercia, D., Kosinski, M., Stillwell, D., \& Crowcroft, J. (2011). Our Twitter Profiles, Our Selves: Predicting Personality with Twitter. 2011 IEEE Third Int'l Conference on Privacy, Security, Risk and Trust and 2011 IEEE Third Int'l Conference on Social Computing, 180-185. https://doi.org/10.1109/PASSAT/SocialCom.2011.26

Ratnavalli, E., Brayne, C., Dawson, K., \& Hodges, J. R. (2002). The prevalence of frontotemporal dementia. Neurology, 58(11), 1615-1621. https://doi.org/10.1212/wnl.58.11.1615

Rauthmann, J. F., Gallardo-Pujol, D., Guillaume, E. M., Todd, E., Nave, C. S., Sherman, R. A., Ziegler, M., Jones, A. B., \& Funder, D. C. (2014). The Situational Eight DIAMONDS: A taxonomy of major dimensions of situation characteristics. Journal of Personality and Social Psychology, 107(4), 677-718. https://doi.org/10.1037/a0037250

Ree, M. J., \& Earles, J. A. (1992). Intelligence Is the Best Predictor of Job Performance. Current Directions in Psychological Science, 1(3), 86-89. https://doi.org/10.1111/1467-8721.ep10768746

Reiner, M., Niermann, C., Jekauc, D., \& Woll, A. (2013). Longterm health benefits of physical activity-A systematic review of longitudinal studies. BMC Public Health, 13, 813. https://doi. org/10.1186/1471-2458-13-813

Saeb, S., Zhang, M., Karr, C. J., Schueller, S. M., Corden, M. E., Kording, K. P., \& Mohr, D. C. (2015). Mobile Phone Sensor Correlates of Depressive Symptom Severity in Daily-Life Behavior: An Exploratory Study. Journal of Medical Internet Research, 17(7), e175. https://doi. org/10.2196/jmir.4273

Sariyska, R., Rathner, E.-M., Baumeister, H., \& Montag, C. (2018). Feasibility of Linking Molecular Genetic Markers to Real-World Social Network Size Tracked on Smartphones. Frontiers in Neuroscience, 12. https://doi.org/10.3389/fnins.2018.00945

Scarmeas, N., Luchsinger, J. A., Schupf, N., Brickman, A. M., Cosentino, S., Tang, M. X., \& Stern, Y. (2009). Physical activity, diet, and risk of Alzheimer disease. JAMA, 302(6), 627-637. https://doi.org/10.1001/ jama.2009.1144

Schwartz, H. A., Eichstaedt, J. C., Kern, M. L., Dziurzynski, L., Ramones, S. M., Agrawal, M., Shah, A., Kosinski, M., Stillwell, D., Seligman, M. E. P., \& Ungar, L. H. (2013). Personality, Gender, and Age in the Language of Social Media: The Open-Vocabulary Approach. PLOS ONE, 8(9), e73791. https://doi.org/10.1371/journal.pone.0073791

Settanni, M., \& Marengo, D. (2015). Sharing Feelings Online: Studying Emotional Well-Being via Automated Text Analysis of Facebook Posts. Frontiers in Psychology, 6, 1045. https://doi.org/10.3389/ fpsyg.2015.01045

Stachl, C., \& Bühner, M. (2015). Show me how you Drive and I'll Tell you who you are Recognizing Gender Using Automotive Driving Parameters. Procedia Manufacturing, 3, 5587-5594. https://doi. org/10.1016/j.promfg.2015.07.743

Stachl, C., Hilbert, S., Au, J.-Q., Buschek, D., Luca, A. D., Bischl, B., Hussmann, H., \& Bühner, M. (2017). Personality Traits Predict Smartphone Usage. European Journal of Personality, 31(6), 701-722. https://doi.org/10.1002/per.2113

Torous, J., Onnela, J.-P., \& Keshavan, M. (2017). New dimensions and new tools to realize the potential of RDoC: Digital phenotyping via smartphones and connected devices. Translational Psychiatry, 7(3), e1053. https://doi.org/10.1038/tp.2017.25Wang, J., Gu, B. J., Masters, C. L., \& Wang, Y.-J. (2017). A systemic view of Alzheimer diseaseInsights from amyloid- $\beta$ metabolism beyond the brain. Nature Reviews Neurology, 13(10), 612-623. https://doi.org/10.1038/nrneurol.2017.111

Wikipedia.org (2019). https://en.wikipedia.org/wiki/Facebook-Cambridge_Analytica_data_scandal (accessed on 20th December 2019)

Yarkoni, T. (2012). Psychoinformatics: New Horizons at the Inter- face of the Psychological and Computing Sciences. Current Directions in Psychological Science, 21(6), 391-397. https://doi. org/10.1177/0963721412457362

Zuboff, S. (2015). Big other: Surveillance Capitalism and the Prospects of an Information Civilization: Journal of Information Technology. https://doi.org/10.1057/jit.2015.5

Zuboff, S. (2019). The Age of Surveillance Capitalism: The Fight for the Future at the New Frontier of Power (01 ed.). Profile Books.

\section{* Corresponding author}

\section{Prof. Dr. Christian Montag}

Institute for Psychology and Education

Helmholtzstr. 8/1

Ulm University

89081 Ulm

Germany

Telephone +49-731-50 26550

Fax +49-731-50 32759

E-Mail: christian.montag@uni-ulm.de

The authors report no conflicts of interest with this paper.

Nevertheless, for reasons of transparency, Dr. Montag mentions that he has received (to Ulm University and earlier University of Bonn) grants from agencies such as the German Research Foundation (DFG). Dr. Montag has performed grant reviews for several agencies; has edited journal sections and articles; has given academic lectures in clinical or scientific venues or companies; and has generated books or book chapters for publishers of mental health texts. For some of these activities he received royalties, but never from the gaming or social media industry. Dr. Montag mentions that he is part of a discussion circle (Digitalität und Verantwortung: https://about.fb.com/de/news/h/gespraechskreis-digitalitaet-und-verantwortung/) debating ethical questions linked to social media, digitalization and society/democracy at Facebook. In this context, he receives no salary for his activities. Finally, he mentions that he currently functions as independent scientist on the scientific advisory board of the Nymphenburg group. This activity is financially compensated.

Outside the scope of the present paper, Dr. Elhai notes that he receives royalties for several books published on posttraumatic stress disorder (PTSD); is a paid, full-time faculty member at University of Toledo; is a paid, visiting scientist at Tianjin Normal University; occasionally serves as a paid, expert witness on PTSD legal cases; and receives grant research funding from the U.S. National Institutes of Health and Department of Defense.

\section{Funding information}

There was no funding in support of the study.

\section{Author contributions}

CM conceptualized and wrote the paper, and JDE edited the paper. 